\title{
Histological types and significance of bronchial epithelial dysplasia
}

\author{
Guo F Wang ${ }^{1}$, Mao D Lai ${ }^{2}$, Ren R Yang ${ }^{3}$, Pei H Chen ${ }^{1}$, Yong Y Su ${ }^{1}$, Bing J Lv², Li P Sun ${ }^{1}$, \\ Qiong Huang ${ }^{2}$ and Shui ZH Chen ${ }^{1}$ \\ ${ }^{1}$ Department of Pathology, Second Affiliated Hospital, School of Medicine, Zhejiang University, Hangzhou, \\ China; ${ }^{2}$ Department of Pathology and Pathophysiology, School of Medicine, Zhejiang University, Hangzhou, \\ China and ${ }^{3}$ Department of Thoracic Surgery, 117 Hospital of PLA, Hangzhou, China
}

\begin{abstract}
Pulmonary epithelium is known to undergo a preneoplastic process prior to the development of lung carcinoma. Squamous dysplasia and atypical adenomatous hyperplasia have been identified and classified as preinvasive lesions of squamous cell carcinoma and peripheral pulmonary adenocarcinoma, respectively. However, these commonly recognized preinvasive lesions do not completely explain the development of all histological types of lung carcinoma. By examining 114 resection lung specimens, we concluded that there are four histological patterns of bronchial epithelial dysplasia based on morphological features (basal cell dysplasia, columnar cell dysplasia, bronchial epithelial dysplasia with transitional differentiation, and squamous dysplasia). The histological patterns were further characterized by immunohistochemistry. Basal cell dysplasia was focally positive for cytokeratin (CK) 17 and 10/13; columnar cell dysplasia was generally positive for CK7, 8, and 18; bronchial epithelial dysplasia with transitional differentiation had a heterogeneous immunoprofile, while squamous dysplasia was positive for CK10/13 and focally positive for CK17. Various degrees of abnormal expression of p53 and Ki-67 were found in the different types of bronchial epithelial dysplasia. The cases were divided into three groups based on degree and extent of bronchial epithelial dysplasia. By Crosstabs McNemar test, the Mann-Whitney U-test (for two independent groups), the KruskalWallis one-way nonparametric ANOVA (for $>2$ independent groups) and Spearman correlation analysis, the degree and extent of bronchial epithelial dysplasia was shown to be positively correlated with the incidence of bronchogenic carcinoma and multifocal primary lung carcinoma $(P<0.05)$. These findings indicated the following: (1) bronchial epithelium can develop various patterns of dysplasia with abnormal/ambiguous cell differentiation and abnormal expressions of p53 and Ki-67. Thus, these bronchial epithelial dysplastic lesions may represent a preneoplastic process. (2) The degree of bronchial epithelial dysplasia may significantly predispose individuals to bronchogenic carcinoma and multifocal primary lung carcinoma.
\end{abstract}

Modern Pathology (2006) 19, 429-437. doi:10.1038/modpathol.3800553; published online 3 February 2006

Keywords: bronchial; epithelium; dysplasia; lung carcinoma

Lung cancer is the most common fatal malignancy worldwide. ${ }^{1}$ Its incidence and mortality rate are the highest among all cancer types for both males and females in certain areas in China, ${ }^{2}$ but its underlying mechanism and natural progression are not yet fully understood. Experimentation has revealed that bronchial and alveolar epithelial cells undergo multiple morphological and molecular changes before the overt expression of lung cancer. ${ }^{3-10}$ However, only squamous dysplasia of bronchial

Correspondence: Professor MD Lai, MD, Department of Pathology and Pathophysiology, School of Medicine, Zhejiang University, 353 Yan'an Road, Hangzhou 310031, China.

E-mail: lmd@zju.edu.cn

Received 28 July 2005; revised and accepted 21 December 2005; published online 3 February 2006 epithelium and atypical adenomatous hyperplasia (AAH) have been extensively investigated ${ }^{11-17}$ and listed as precursors of so-called central squamous cell carcinoma (SCC) or adenocarcinoma in the World Health Organization (WHO) histological classification of lung and pleural tumors. ${ }^{18}$ The origin and development of central (ie bronchogenic) non-SCC and peripheral SCC are still poorly understood as yet. In this paper, histological and immunohistochemical studies were carried out on 114 surgically resected lung specimens with primary carcinoma with the objectives of: clarifying the types of bronchial epithelial dysplasia; demonstrating abnormal expressions of p53 and Ki-67; and, using statistical analysis, investigating the possible relationship of these lesions to bronchogenic carcinoma. 


\section{Materials and methods}

\section{Lung Resection Specimens}

A total of 114 patients (86 males and 28 females) with primary lung carcinoma had complete pneumonectomy (2 right, 12 left) or lobectomy (2 right upper middle lobes, 7 right lower middle lobes, 17 right upper lobes, 19 right lower lobes, 9 right middle lobes, 30 left upper lobes, and 16 left lower lobes) between February 2000 and November 2001 at the Second Affiliated Hospital of Zhejiang University, Hangzhou. Patient age was 32-76 years (mean, 58.8 years and median, 60 years). All patients or relatives gave informed consent with regard to the objectives, nature, and consequences of the study.

The 114 cases included 101 cases of solitary lung carcinoma and 13 cases of multiple primary lung carcinoma (MPLC). For statistical analysis of the correlation of bronchial epithelial dysplasia with bronchogenic carcinoma, solitary primary lung carcinomas were grouped into bronchogenic carcinoma (90 cases, including 35 SCC, 26 adenocarcinomas, 16 large-cell carcinomas, and 13 small-cell lung carcinomas) and bronchioloalveolar adenocarcinoma (BAC, 11 cases). Lung carcinoma typing was based on criteria from the WHO classification of lung tumors. ${ }^{18}$

MPLC is defined by the presence of multiple separate (noncontiguous) foci of lung carcinoma without morphological similarity or transition. In this study, metastatic tumor was excluded by clinicopathological data such as previous tumor history, X-ray examination, and histological assessment. All the above criteria were required for a case to be diagnosed as MPLC.

\section{Pathological Examination}

For each lung specimen, 3-4-mm-thick tissue blocks were serially dissected from the proximal bronchial resection margin to the macroscopically visible peripheral bronchiole along the bronchial tree (including those destroyed by carcinoma) and consecutively numbered. On average, 70 tissue blocks were obtained from each upper and lower lobe of the left and right lungs, and 30 from each right middle lobe. All the blocks were formalinfixed and embedded in paraffin wax according to standard procedures and sections stained in hematoxylin and eosin examined histologically.

\section{Immunohistochemical Staining}

The Envision ${ }^{\mathrm{TM}}$ two-step staining protocol was used. Briefly, after antigen retrieval via boiling in $\mathrm{pH} \quad 6.010 \mathrm{mmol} / \mathrm{l}$ citrate buffer for $20 \mathrm{~min}$, the slides were incubated with diluted primary antibody for $90 \mathrm{~min}$, then incubated with the secondary antibody for $30 \mathrm{~min}$ at room temperature and developed with DAB. Positive and negative controls were set up simultaneously. Antibodies used in this study included cytokeratin (CK) 7 (OVTL 12/30, dilution 1:100), CK8 (35 $\beta$ H111, 1:100), CK10/13 (DE-K13, 1:100), CK17 (E3, 1:100), CK18 (DC10, 1:100), surfactant apoprotein A (SP-A, PE10, 1:100), chromogranin A (CgA, DAK-A3, 1:200), synaptophysin (Syn, SY38, 1:100), bcl-2 (124, 1:100), thyroid transcription factor-1 (TTF-1, 8G7G3/11, 1:150), p53 (DO-7, 1:300), and Ki-67 (MIB-1, 1:100). All antibodies were from DAKO (Denmark).

Positive immunostaining was recorded when cytoplasm and/or cell membranes were stained for the CKs, SP-A, CgA, Syn, and bcl-2, and nuclei for TTF-1, p53, and Ki-67.

\section{Statistical Analysis}

Data were analyzed using SPSS version 11.0. The following statistical tests were applied, where appropriate, in the data analysis: McNemar's test, the Mann-Whitney $U$-test (for two independent groups), the Kruskal-Wallis one-way nonparametric ANOVA (for $>2$ independent groups), and the Spearman rank correlation test. The threshold significance level used was $P \leq 0.05$ (two-tailed).

\section{Results}

\section{Criteria for Classifying Types of Bronchial Epithelial Dysplasia}

Bronchial basal cells were normally round or oval, and attached to the basement membrane in a single layer. The nuclei were generally equal to and never larger than 1.5 times the diameter of a normal resting small lymphocyte. Columnar epithelial cells were positioned on the basal cell layer, vertically towards the luminal surface of the bronchial mucosa. A few cells containing intracytoplasmic mucin were interspersed among them. The nuclear width of a normal oval-shaped columnar cell approximated to the nuclear diameter of a normal basal cell. In the proximal lobe bronchus, columnar cells were arranged in a pseudostratified pattern, with up to three cell layers. In segmental and more distal subsegmental bronchi, columnar cells were often arranged in a monolayer pattern. Normal basal cells and columnar cells were morphologically distinguishable, and had fine nuclear chromatin and inconspicuous nucleoli (Figure 1).

Bronchial epithelial dysplasia was identified on the basis of nuclear atypia and irregular cell arrangement. Nuclear atypia was recognized by: enlarged nuclear diameter (or nuclear width of a columnar/oval cell) reaching at least twice the diameter of a normal small resting lymphocyte; increased nucleo-cytoplasmic ratios; irregularities of 
nuclear outline; dark or coarsely uneven nuclear chromatin; and one or more prominent nucleoli. Fibrous hyperplasia and neovascularization were seen beneath some of the dysplastic epithelium. However, increases in the numbers of dysplastic cells and numbers of cell layers were not consistently related to the degree of bronchial epithelial dysplasia.

Based on morphological features, bronchial epithelial dysplasia may be categorized into basal cell dysplasia, columnar cell dysplasia, bronchial epithelial dysplasia with transitional differentiation (bronchial epithelial dysplasia TD-type), and squamous dysplasia.

\section{Basal cell dysplasia}

Normal basal cells were replaced by dysplastic basal cells with a round, oval, or irregular appearance, without intercellular bridges and differentiation towards bronchial columnar cell, squamous stratification, and keratinization (Figure 2). The dysplastic cell groups were patchy.

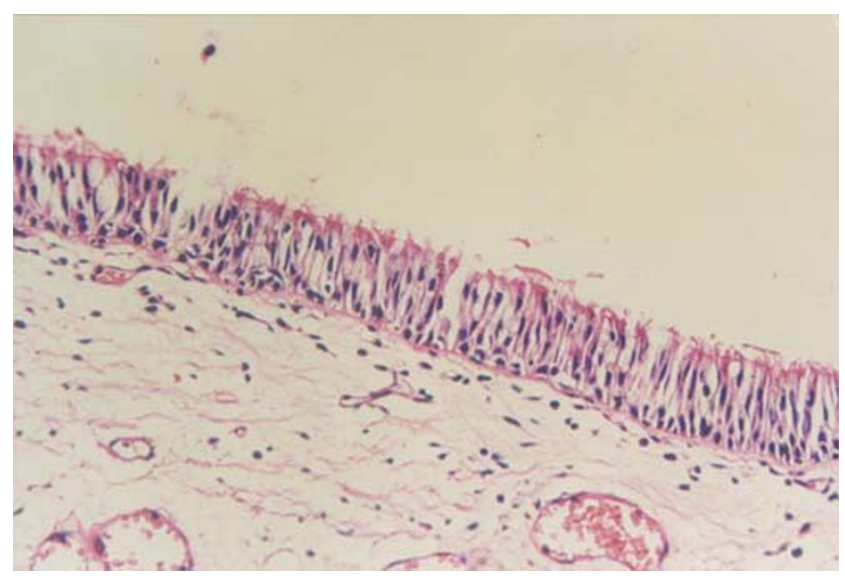

Figure 1 Normal bronchial epithelium $(\mathrm{H} \& \mathrm{E}, \times 200)$.

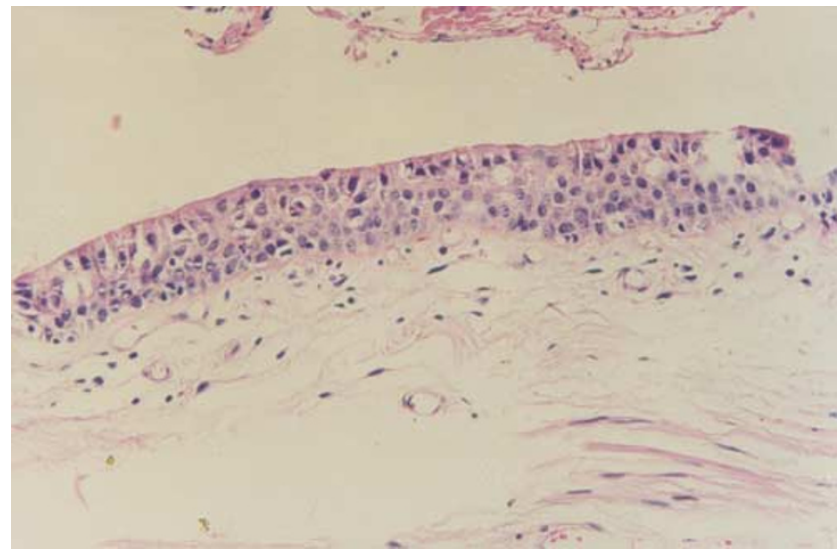

Figure 2 Basal cell dysplasia, low-grade. Enlarged nuclei had diameters more than twice that of a small resting lymphocyte and had obvious nucleoli and nuclear chromatin. Columnar epithelial cells were present on the luminal surface of the dysplastic basal cells $(\mathrm{H} \& \mathrm{E}, \times 200)$.

\section{Columnar cell dysplasia}

Bronchial columnar cell dysplasia was located on the basal cell layer and cells showed a columnar or oval outline. They appeared either in a verruciform pattern without stromal stalks, a flat lesion with increased epithelial cell layers of the involved mucosa (Figure 3), or a cribriform pattern (Figure 4). Intracytoplasmic mucin was present in some of the dysplastic columnar cells.

\section{Bronchial epithelial dysplasia with transitional differentiation}

This pattern of bronchial epithelial dysplasia exhibited some, but not all, of the morphological features of basal cell, columnar cell, and/or squamous epithelium, and seemed to be in morphological transition between them-hence the term bronchial epithelial dysplasia with transitional differentiation (bronchial epithelial dysplasia TDtype) was introduced. Diagnosis was made when the bronchial epithelium displayed full-thickness dysplasia with homogeneous cytologic morphology

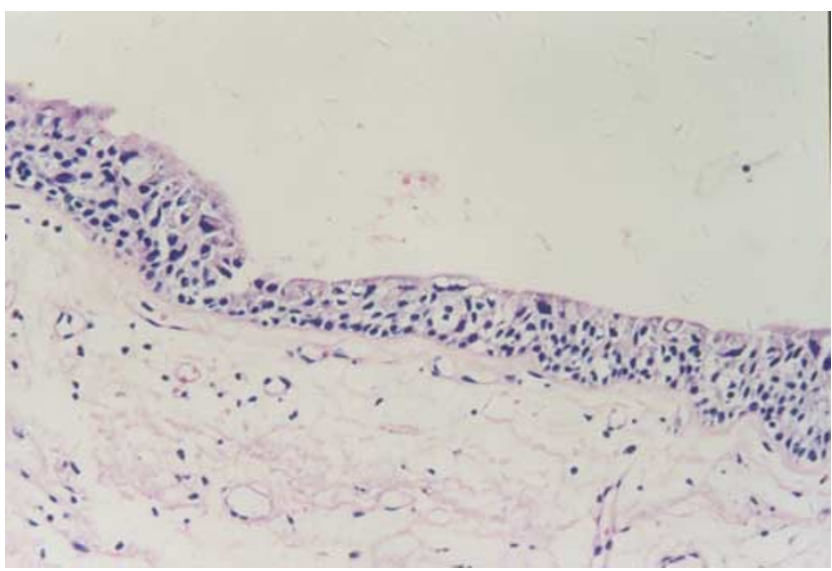

Figure 3 Columnar cell dysplasia, low-grade, with focal highgrade dysplasia. Intracellular mucin was visible. A single layer of basal cells was seen beneath the dysplastic columnar cells (H\&E, $\times 200$ ).

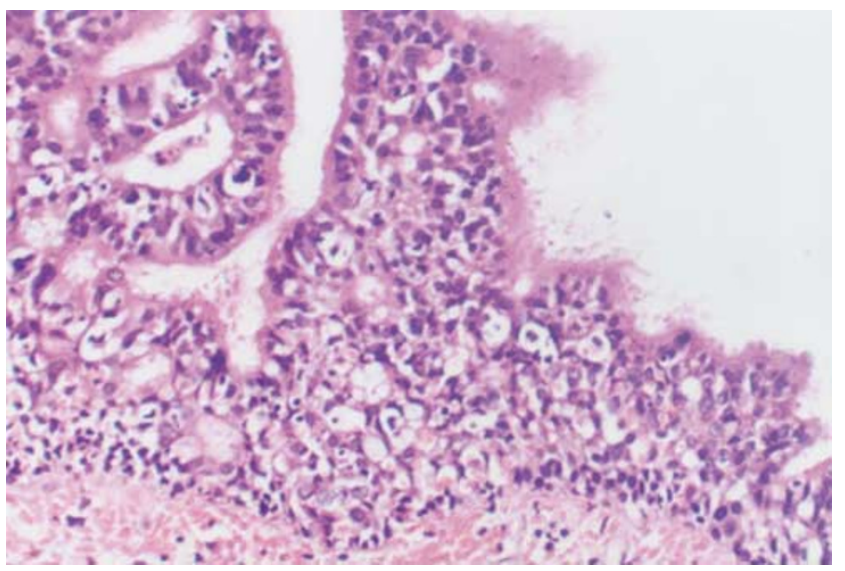

Figure 4 Columnar cell dysplasia, cribriform-like structure with infiltration of a few inflammatory cells $(\mathrm{H} \& \mathrm{E}, \times 200)$. 


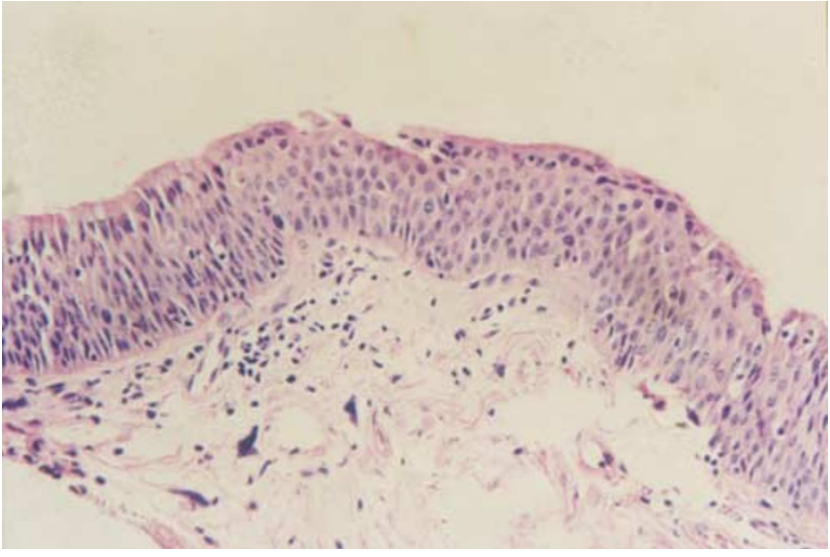

Figure 5 Bronchial epithelial dysplasia TD-type, low-grade (H\&E, $\times 200$ ).

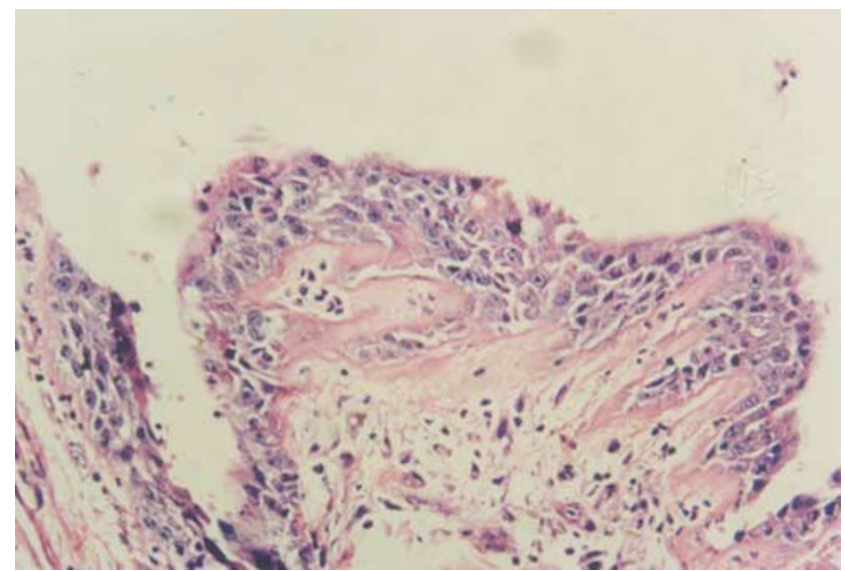

Figure 6 Bronchial epithelial dysplasia TD-type, high-grade $(\mathrm{H} \& \mathrm{E}, \times 200)$.

throughout the epithelium without intercellular bridges, or with focal intercellular bridges without squamous stratification and keratinization (Figures 5 and 6). Generally, pseudomultilayering or multilayer structures were frequent in those examples with intercellular bridges (Figure 7). Dysplastic cells were columnar, oval, or round. Intracellular mucin vacuoles were present in some cells.

\section{Squamous dysplasia}

Squamous dysplasia (Figure 8) was identified by criteria described in the WHO classification of lung and pleural tumors. ${ }^{18}$ However, we found that a small proportion of squamous dysplasia displayed marked atypia, but with little increase in cell number and layers.

\section{Grading of Bronchial Epithelial Dysplasia}

A two-tiered grading system, low- and high-grade dysplasia, was adopted for the lesions described above, based on degrees of nuclear atypia and irregularity of cell arrangement.

Low-grade dysplasia showed only mild to moderate nuclear atypia with a mildly irregular cell

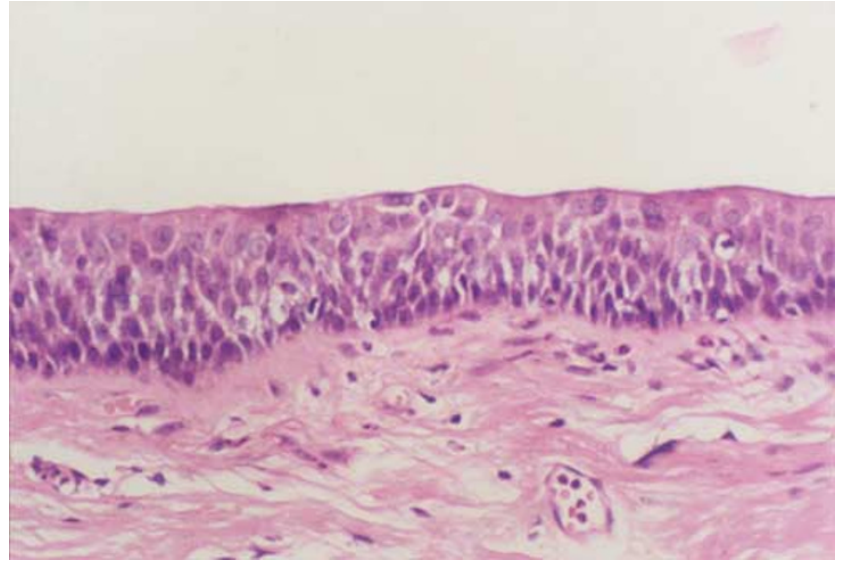

Figure 7 Bronchial epithelial dysplasia TD-type, low-grade, with scattered high-grade dysplastic cells. Intercellular bridges were present, but squamous stratification absent $(\mathrm{H} \& \mathrm{E}, \times 200)$.

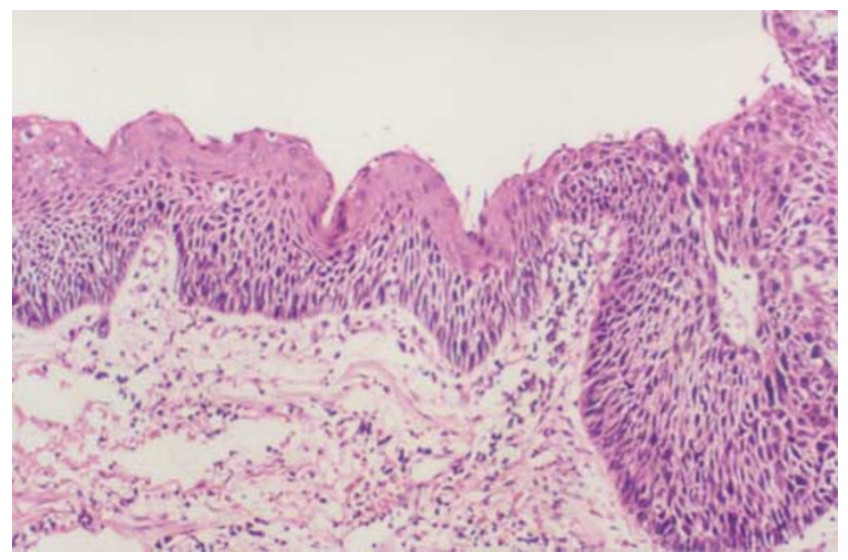

Figure 8 Squamous dysplasia. On the left, low-grade, and on the right high-grade dysplasia $(\mathrm{H} \& \mathrm{E}, \times 200)$.

arrangement: enlarged nuclei less than twice the diameter of a normal epithelial cell (or the width for a columnar/oval cell), mild to moderate pleomorphism with dense chromatin, and inconspicuous nucleoli (Figures 2-5 and 7).

High-grade dysplasia showed marked nuclear atypia and a very disordered cell arrangement. Nuclear diameters were twice, or larger than, the normal value. Dysplastic cells had obvious nuclear pleomorphism, coarse chromatin, and prominent and/or multiple nucleoli (Figure 6). High-grade dysplastic cells appeared as clusters, or were scattered throughout an area of low-grade dysplasia (Figures 3 and 7 ).

In the case of squamous dysplasia, low-grade was confirmed when dysplastic cells were confined to the lower half of the involved epithelium (see the left part of Figure 8), whereas high-grade dysplasia was confirmed when almost the whole thickness of the squamous epithelium was involved by dysplastic cells (see the right part of Figure 8). Accordingly, low-grade dysplasia was found in 75 cases, and high-grade dysplasia in 25. 


\section{Immunohistochemistry Findings}

Tissue blocks showing extensive and a high degree of bronchial epithelial dysplasia in the first section were used for subsequent immunohistochemical studies. Approximately 15-20 histological sections were re-cut serially from each of the selected tissue blocks. One of them was stained with hematoxylin and eosin, and observed microscopically to confirm the presence of the aforementioned classic dysplastic lesions. Those with little or no bronchial epithelial dysplasia were excluded from immunoprofiling. As a consequence of this procedure, there were 53 histologic sections from 26 lung specimens available for immunohistochemical study. Each section contained at least one of the aforementioned classic types of bronchial epithelial dysplasia. The normal bronchial epithelium between dysplastic foci provided control tissue for normal basal cells and columnar cells. Additionally, two cases of normal esophageal epithelium were selected to provide normal squamous epithelial controls. Immunohistochemical expression of each of the aforementioned antibodies, especially for Ki-67 and p53, was defined by the presence of unambiguously positive-staining cells, regardless of their number.

Normal bronchial epithelial cells and squamous epithelium showed typical immunostaining patterns, with basal cells positive for CK17, columnar cells positive for CK7, 8, and 18, and squamous cells positive for CK10/13.

Immunostaining in dysplastic epithelium was essentially similar to that of the normal controls, but showed some changes in that basal cell dysplasia was focally positive for CK10/13, and squamous dysplasia was focally positive for CK17, and occasionally positive for CK8 and 18. However, some dysplastic bronchial epithelial cells were negative for corresponding specific markers, even for all CKs above.

Immunostaining was heterogeneous in bronchial epithelial dysplasia TD-type. Some of these lesions were positive for single members of the CK family (CK10/13, 17, 7, 8, or 18), and some positive for all of them (Figures 9 and 10). There were different degrees of staining, and in those dysplastic foci showing immunoreactivity for multiple CKs, different cells stained for different CKs.

All types of bronchial epithelial dysplasia were negative for TTF-1, SPA, CgA, and Syn.

p53 and Ki-67 immunostaining was identified in various types of bronchial epithelial dysplasia (Figures 11 and 12, Table 1). Ki-67 immunostaining was more widespread and had a stronger staining intensity than p53. The level of Ki-67 expression was significantly higher than that of p53 (McNemar test, $P=0.013$ ) (Table 2). Bcl-2 was expressed in only $46.2 \%$ of normal basal cells $(12 / 26)$ and was rarely expressed in other types of normal and dysplastic bronchial epithelia.

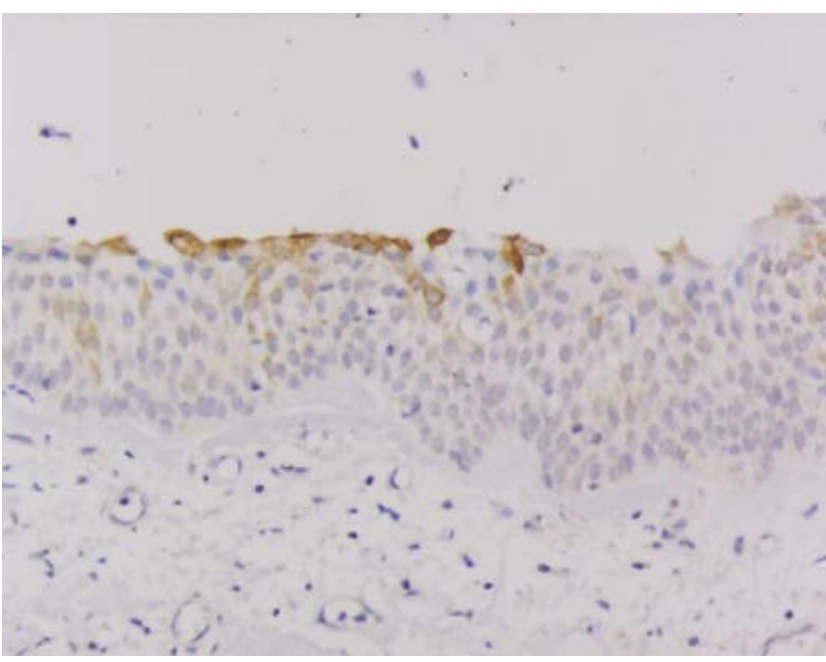

Figure 9 CK10/13 immunostaining of bronchial epithelial dysplasia TD-type. The superficial flat cells showed strong positive staining for CK10/13, which indicated squamous differentiation, while other cells showed weak positive staining for CK10/13 $\left(\right.$ Envision $\left.^{\mathrm{TM}}, \times 200\right)$.

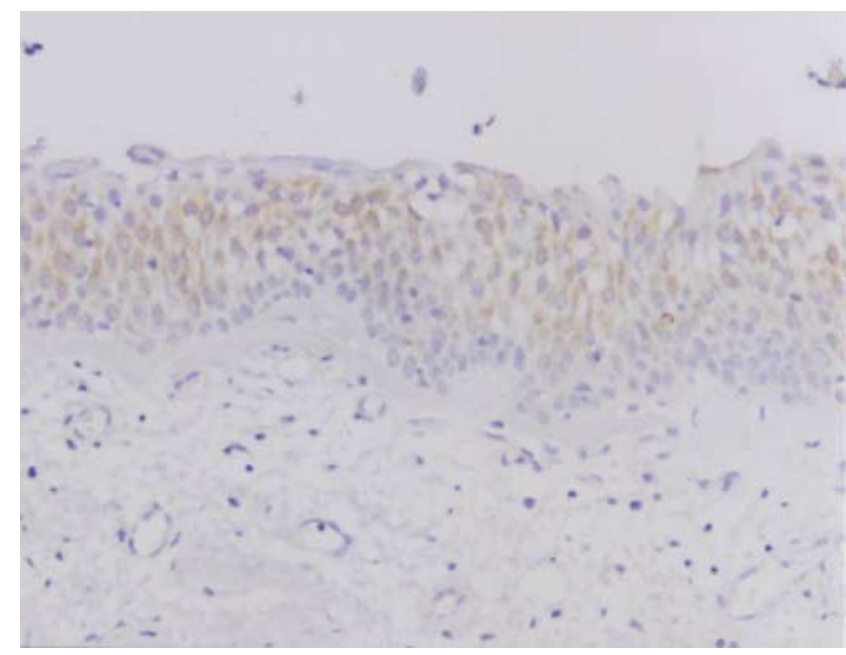

Figure 10 CK8 immunostaining of bronchial epithelial dysplasia TD-type. The figure showed weak to intermediate positivity for CK8 (same field as in Figure 9) $\left(\right.$ Envision $^{\mathrm{TM}}, \times 200$ ).

\section{Distribution of Bronchial Epithelial Dysplasia}

The incidence of the various types of bronchial epithelial dysplasia identified in the current study is given in Table 3. Different types and degrees of bronchial epithelial dysplasia could be found in the same bronchus, or in the same histological section. Lesions of the same or different types of bronchial epithelial dysplasia were sometimes separated from each other by areas of normal bronchial epithelium, or they were sometimes contiguous without normal intervening tissue. In such cases, one focus of dysplasia graded into another. Intriguingly, highgrade bronchial epithelial dysplasia was generally seen in the cases with extensive low-grade dysplasia. Otherwise, high-grade dysplasia was rare. 


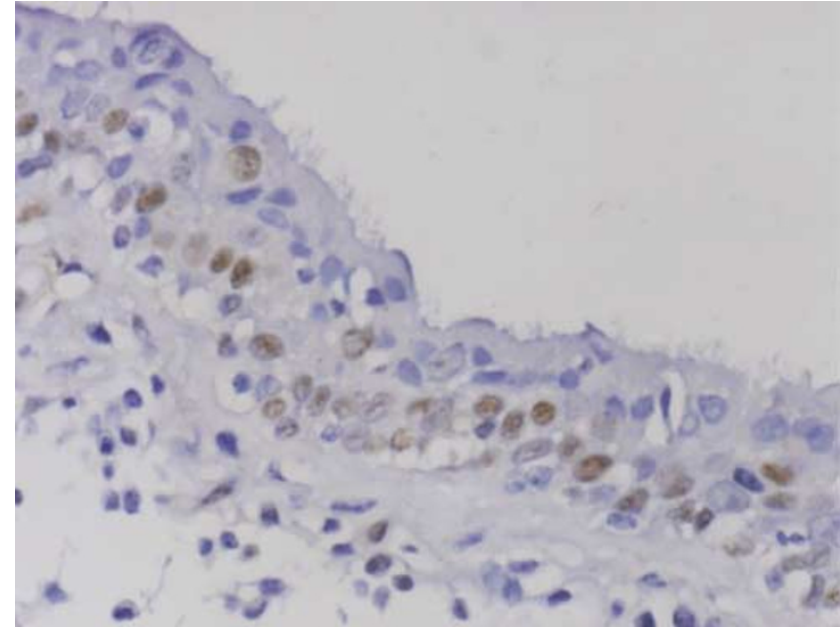

Figure 11 Ki-67 immunostaining of bronchial epithelial dysplasia (Envision $\left.{ }^{\mathrm{TM}}, \times 400\right)$

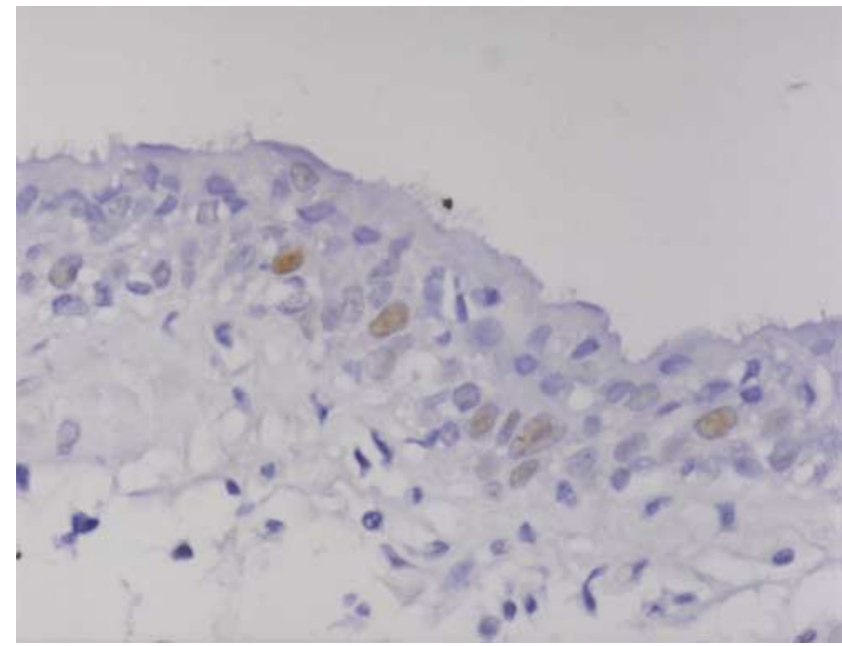

Figure 12 p53 immunostaining of bronchial epithelial dysplasia (Figures 11 and 12 are from the same field and the same lesion. Note that the p53-positive cells are fewer than Ki-67-positive cells) (Envision $\left.{ }^{\mathrm{TM}}, \times 400\right)$.

In view of these findings and in order to analyze the correlation of the degrees of bronchial epithelial dysplasia to bronchogenic carcinoma, the cases in this study were divided into three groups on the basis of the extent and degree of bronchial epithelial dysplasia. Group I had normal bronchial epithelium with or without simple hyperplasia, or occasionally small foci of low-grade dysplasia. Group II had bronchial epithelium with extensive low-grade dysplasia (lacking any foci of high-grade dysplasia), or showed foci of low-grade dysplasia with small groups of cells (several or dozens) exhibiting highgrade dysplasia. Group III had extensive low-grade dysplasia plus variable foci of high-grade dysplasia. Here, extensive low-grade dysplasia was defined when at least $40 \%$ of examined slides showed dysplasia and that more than $20 \%$ of those slides
Table 1 Expression of p53 and Ki-67 in the foci of bronchial epithelial dysplasia

\begin{tabular}{|c|c|c|c|c|c|}
\hline \multirow[t]{2}{*}{$\begin{array}{l}\text { Case } \\
\text { no. }\end{array}$} & \multirow[t]{2}{*}{$\begin{array}{c}\text { Types of } \\
\text { dysplasia }\end{array}$} & \multicolumn{2}{|c|}{$\begin{array}{l}\text { Percent of positive } \\
\text { cells }^{\mathrm{a}}\end{array}$} & \multicolumn{2}{|c|}{ Pattern of distribution } \\
\hline & & Ki-67 & P53 & $K i-67$ & P53 \\
\hline 1 & SD & $>10 \%$ & $<10 \%$ & Patchy & Patchy \\
\hline 2 & TD-type & $<10 \%$ & $<10 \%$ & Scattered & Scattered \\
\hline 3 & TD-type & $>10 \%$ & $<10 \%$ & Patchy & Patchy \\
\hline \multirow[t]{2}{*}{4} & TD-type & $<10 \%$ & $<10 \%$ & Patchy & Patchy \\
\hline & BCD & $<10 \%$ & Negative & Scattered & \\
\hline \multirow[t]{3}{*}{5} & TD-type & $<10 \%$ & $<10 \%$ & Scattered & Patchy \\
\hline & CCD & $>10 \%$ & $>10 \%$ & Scattered & Scattered \\
\hline & BCD & $<10 \%$ & $<10 \%$ & Scattered & Scattered \\
\hline \multirow[t]{2}{*}{6} & BCD & $<10 \%$ & $<10 \%$ & Scattered & Scattered \\
\hline & TD-type & $<10 \%$ & $<10 \%$ & Patchy & Patchy \\
\hline \multirow[t]{3}{*}{7} & SD & $<10 \%$ & Negative & Scattered & \\
\hline & CCD & $>10 \%$ & $>10 \%$ & Scattered & Scattered \\
\hline & TD-type & $<10 \%$ & Negative & Scattered & \\
\hline \multirow[t]{2}{*}{8} & SD & $>10 \%$ & $<10 \%$ & Scattered & Patchy \\
\hline & TD-type & $<10 \%$ & $<10 \%$ & Scattered & Patchy \\
\hline \multirow[t]{3}{*}{9} & CCD & $<10 \%$ & $<10 \%$ & Scattered & Patchy \\
\hline & BCD & $<10 \%$ & Negative & Scattered & \\
\hline & TD-type & $<10 \%$ & Negative & Scattered & \\
\hline \multirow[t]{3}{*}{10} & $\mathrm{SD}$ & $>10 \%$ & $<10 \%$ & Patchy & Patchy \\
\hline & CCD & $>10 \%$ & $<10 \%$ & Scattered & Scattered \\
\hline & BCD & $<10 \%$ & $<10 \%$ & Scattered & Scattered \\
\hline 11 & BCD & $>10 \%$ & Negative & Patchy & \\
\hline 12 & TD-type & $>10 \%$ & $<10 \%$ & Patchy & Patchy \\
\hline \multirow[t]{2}{*}{13} & SD & $>10 \%$ & Negative & Patchy & \\
\hline & TD-type & $>10 \%$ & Negative & Patchy & \\
\hline \multirow[t]{2}{*}{14} & SD & $<10 \%$ & $<10 \%$ & Patchy & Patchy \\
\hline & TD-type & $<10 \%$ & $<10 \%$ & Patchy & Patchy \\
\hline \multirow[t]{2}{*}{15} & BCD & $>10 \%$ & $<10 \%$ & Patchy & Patchy \\
\hline & TD-type & $>10 \%$ & $<10 \%$ & Patc & Patchy \\
\hline 16 & TD-type & $>10 \%$ & $<10 \%$ & Patchy & Patchy \\
\hline 17 & TD-type & $>10 \%$ & $10 \%$ & Patchy & Patchy \\
\hline 18 & TD-type & $<10 \%$ & Negative & Patchy & \\
\hline 19 & BCD & $<10 \%$ & $<10 \%$ & Scattered & Patchy \\
\hline 20 & CCD & Negative & $>10 \%$ & & Scattered \\
\hline \multirow[t]{2}{*}{21} & BCD & $<10 \%$ & Negative & Patchy & \\
\hline & TD-type & $<10 \%$ & Negative & Patchy & \\
\hline 22 & BCD & $<10 \%$ & $<10 \%$ & Scattered & Scattered \\
\hline 23 & CCD & Negative & $<10 \%$ & & Patchy \\
\hline & CCD & Negative & Negative & & \\
\hline \multirow[t]{2}{*}{25} & TD-type & $<10 \%$ & $<10 \%$ & Patch & Patchy \\
\hline & SD & $<10 \%$ & $<10 \%$ & Patchy & Patchy \\
\hline 26 & CCD & $<10 \%$ & Negative & Scattered & \\
\hline
\end{tabular}

BCD, basal cell dysplasia; CCD, columnar cell dysplasia; TD-type, bronchial epithelial dysplasia with transitional differentiation; SD, squamous dysplasia.

${ }^{\mathrm{a}}$ Percentage $=$ number of immunopositive cells over the total number of dysplastic cells in a given dysplastic lesion.

with dysplasia involved $1 / 3$ more of the internal bronchial circumference. In this study, 39 cases were regarded as Group I, 50 cases as Group II, and 25 cases as Group III.

\section{Correlations of Bronchial Epithelial Dysplasia with Bronchogenic Carcinoma and MPLC}

The incidence of bronchial epithelial dysplasia with bronchogenic carcinoma was significantly higher than with BAC. The degree of bronchial epithelial 
Table 2 Expressions of Ki-67 and p53 in various types of bronchial epithelial dysplasia

\begin{tabular}{lccr}
\hline & No. of foci & Ki-67 (\%) & p53 (\%) \\
\hline BCD & 10 & $10(100.0)$ & $6(60.0)$ \\
CCD & 8 & $5(62.5)$ & $6(75.0)$ \\
TD-type & 17 & $17(100.0)$ & $12(70.6)$ \\
SD & 7 & $7(100.0)$ & $5(71.4)$
\end{tabular}

BCD, basal cell dysplasia; CCD, columnar cell dysplasia; TD-type, bronchial epithelial dysplasia with transitional differentiation; SD, squamous dysplasia.

Comparison of positive rate of Ki-67 with p53, McNemar test, $P=0.013$.

Table 3 Incidence of various types of bronchial epithelial dysplasia in lung specimens bearing primary carcinoma

\begin{tabular}{lccrrr}
\hline & $\begin{array}{c}\text { No. of } \\
\text { cases }\end{array}$ & $B C D(\%)$ & $C C D(\%)$ & \multicolumn{1}{c}{$\begin{array}{c}\text { TD-type } \\
(\%)\end{array}$} & \multicolumn{1}{c}{$S D(\%)$} \\
\hline $\begin{array}{l}\text { MPLCs } \\
\text { Bronchogenic }\end{array}$ & 13 & $1(7.7)$ & $6(46.2)$ & $9(69.2)$ & $2(15.4)$ \\
carcinoma & 90 & $12(13.3)$ & $16(17.7)$ & $48(53.3)$ & $17(18.9)$ \\
$\quad$ SCC & 35 & $6(17.1)$ & $5(14.3)$ & $17(48.6)$ & $7(20.0)$ \\
$\quad$ Non-SCC & 42 & $4(9.5)$ & $9(21.4)$ & $24(57.1)$ & $6(14.3)$ \\
$\quad$ SCLC & 13 & $2(15.4)$ & $2(15.4)$ & $7(53.8)$ & $4(30.8)$ \\
BAC & 11 & $1(9.1)$ & $3(27.3)$ & $3(27.3)$ & 0 \\
\hline
\end{tabular}

BCD, basal cell dysplasia; CCD, columnar cell dysplasia; TD-type, bronchial epithelial dysplasia with transitional differentiation; SD, squamous dysplasia.

Table 4 Correlation of bronchogenic carcinoma and MPLC with bronchial epithelial dysplasia

$\begin{array}{ccc}\begin{array}{c}\text { MPLC }(\%) \\ (\mathrm{n}=13)(1)\end{array} & \begin{array}{c}\text { Bronchogenic } \\ \text { carcinoma }(\%) \\ (\mathrm{n}=90)(2)\end{array} & \begin{array}{c}\text { BAC }(\%) \\ (\mathrm{n}=11)(3)\end{array}\end{array}$

\begin{tabular}{|c|c|c|c|}
\hline \multicolumn{4}{|l|}{ Dysplasia $^{\mathrm{a}}$} \\
\hline Absent & $2(15.4)$ & $30(33.3)$ & $7(63.6)$ \\
\hline Present & $11(84.6)$ & $60(66.7)$ & $4(36.4)$ \\
\hline \multicolumn{4}{|c|}{ Degree of dysplasia ${ }^{\mathrm{b}}$} \\
\hline Group I & $2(15.4)$ & $30(33.3)$ & 7 (63.6) \\
\hline Group II & $4(30.8)$ & $43(47.8)$ & $3(27.3)$ \\
\hline Group III & 7 (53.8) & 17 (18.9) & $1(9.1)$ \\
\hline
\end{tabular}

${ }^{\mathrm{a}}$ Spearman bivariate correlations, $\rho=0.229, P=0.014$; McNemar tests, (2) vs (3) $P<0.0005$.

${ }^{\mathrm{b}}$ Spearman bivariate correlations, $\rho=-0.289, P=0.002$, KruskalWallis test, $\chi^{2}=9.48, P=0.009$; Mann-Whitney $U$-test, (1) vs (2) $Z=-2.369, P=0.018$; (1) vs (3) $Z=-2.645, P=0.011$; (2) vs (3) $Z=-1.820, P=0.069$.

dysplasia was also correlated positively with the incidence of bronchogenic carcinoma and MPLC (Table 4). But no correlation of histological types between bronchial epithelial dysplasia and bronchogenic carcinoma was further identified.

Bronchial epithelial dysplasia was often seen in segmental and subsegmental bronchi, especially in the proximal regions. Dysplasia was also found in lobar bronchi, bronchi and bronchioli, but the incidence in these areas was much lower than in segmental and subsegmental bronchi. The location and degree of bronchial epithelial dysplasia were not associated with distance from the primary lung carcinoma.

\section{Discussion}

Terminology such as atypical hyperplasia, dysplasia, and intraepithelial tumor could be used to describe hyperplastic lesions of epithelial cells. Dysplasia is the preferred term for describing lesions with characteristics of neoplastic hyperplasia, and was introduced in our paper because the hyperplastic lesions identified in our series occurred with primary lung carcinoma, and showed marked nuclear atypia (Figures 2-8), moreover, with frequent abnormal expression of Ki-67 and p53 (Figures 11 and 12, and Table 1).

In 1957 and 1961, Auerbach et $a l^{19,20}$ had described morphological changes in bronchial epithelium by examination of the entire tracheobronchial tree in hundreds of subjects. In comparison with Auerbach, our study was focused on surgical resection lung specimens with primary lung carcinoma, and tissue blocks were taken from the proximal bronchial resection margin to more distal macroscopically visible bronchioles with a much greater number of tissue blocks obtained from each lung lobe: Auerbach took tissue blocks from the trachea to the end of each segmental bronchus on the whole left and right lungs at autopsy.

Our study confirmed the results of previous studies on squamous dysplasia and basal cell dysplasia. ${ }^{19-23}$ We have described in detail and subsequently categorized columnar cell dysplasia and bronchial epithelial dysplasia with transitional differentiation, which was previously described with an ambiguous or different terminology. ${ }^{19,20}$ Bronchial columnar cell dysplasia and bronchial epithelial dysplasia with transitional differentiation showed characteristic morphological features and immunostaining patterns distinct from squamous dysplasia and basal cell dysplasia.

Bronchiolar columnar cell dysplasia had been identified and considered a novel preneoplastic lesion of bronchiolar epithelium by comparative genomic hybridization (CGH) ${ }^{24}$ In the current study, we described morphological features and the immunoprofile of columnar cell dysplasia occurring on segmental and subsegmental bronchi. The distinct characteristic in our series was the presence of basal cells beneath the dysplastic columnar epithelium (Figures 3 and 4): This was different from bronchiolar columnar cell dysplasia occurring on bronchiolar epithelium as described by Ullmann et $a l,{ }^{24}$ and also different from bronchial epithelial dysplasia TD-type showing homogeneous cytologic appearances throughout the whole epithelium (Figures 5 and 6). As for distinguishing columnar 
cell dysplasia from reactive columnar cell hyperplasia, typically, reactive hyperplasia occurred during severe, chronic inflammation of the bronchial mucosa, and only showed increased cell number, dense cell arrangement, and minimal nuclear atypia, the hallmark of dysplasia.

The morphology of bronchial epithelial dysplasia TD-type was described with an ambiguous or different terminology in the literatures, ${ }^{19,20,21,25}$ but has not been satisfactorily characterized. ${ }^{26-28}$ It had intriguing morphological features indicating transitional states of differentiation from basal cell towards bronchial columnar cell, or a tendency toward squamous differentiation. Immunohistochemical findings suggested that this type of bronchial epithelial dysplasia may represent a phenotypic spectrum from modest columnar cell differentiation (retaining nearly all the features of basal cells) almost to columnar cell differentiation or even an intermediate stage between basal cell and columnar cell, frequently with imperfect squamous differentiation, the latter only showing focal intercellular bridges without squamous stratification and keratinization. Bronchial epithelial dysplasia TD-type differed morphologically from complete/ typical squamous dysplasia exhibiting intercellular bridges, squamous stratification, keratinization, and, sometimes, pearl formation (Figure 8), and from regenerating bronchial epithelium which McDowell et $a l^{29}$ had studied and described in female Syrian golden hamster tracheal epithelium. The key differences between bronchial epithelial dysplasia TD-type and regenerating bronchial epithelium were that the former exhibited distinct nuclear atypia with coarse nuclear chromatin and prominent nucleoli and irregular cell arrangement, which were absent in regenerating bronchial epithelium. In our series, some hyperplastic bronchial epithelium was considered to be regenerating, which showed a uniform cuboidal to short columnar cell appearance, fine nuclear chromatin, inconspicuous nucleoli, and regular cell arrangement, generally of one or two cell layers, and generally without cilia. In this period, one cannot distinguish basal cells from columnar cells morphologically. With the progression of epithelial repair, these undifferentiated cells will further differentiate and finally become normal bronchial epithelium, showing normal basal cell and columnar cell appearance.

Bronchial epithelial dysplasia TD-type was categorized as a discrete type of bronchial epithelial dysplasia in this paper owing to its high incidence, and distinct morphological and immunostaining features. Moreover, it frequently showed Ki-67 and p53 positive immunostaining (Figures 11 and 12, Table 1). Previous studies showed that different patterns of bronchial epithelial dysplasia (ie nonsquamous carcinoma in situ and high-grade squamous lesions) displayed combined expressions of p53, Rb, Ras, and bcl-2. ${ }^{30}$ These results indicated that, apart from squamous dysplasia, a well- accepted preinvasive lesion for squamous lung carcinoma, there were other nonsquamous preneoplastic pathways.

Changes in CK expression in our results were consistent with those reported in the literature. ${ }^{31,32}$ The changes in our study were especially demonstrated in bronchial epithelial dysplasia TD-type, which showed diverse and heterogeneous CK immunostaining. These results suggested that bronchial epithelial dysplasia was often accompanied by a disordered direction of cell differentiation, a phenomenon frequently observed in lung carcinomas.

The distribution of bronchial epithelial dysplasia as observed in our study was consistent with those observed by Auerbach. ${ }^{19,20}$ From the observed distribution of bronchial epithelial dysplasia and the results of statistical analysis on the correlation of these dysplasia with lung carcinomas (Table 4), we were able to comment on the relation of bronchial epithelial dysplasia to bronchogenic carcinoma: it was concluded that bronchial epithelium may develop various types and degrees of dysplasia synchronously or metachronously, and that bronchial epithelial dysplasia was associated with the development of bronchogenic carcinoma. These results also provided morphologic evidence for the theory of a multi-step process of lung carcinoma development, and may help to explain the development of MPLC and manifestations reported by Janout. $^{33}$

Although we described histologic types and immunostaining findings of bronchial epithelial dysplasia and confirmed the positive correlation of bronchial epithelial dysplasia with bronchogenic carcinoma using statistical analysis, further investigation to include the molecular aspects should be carried out to elucidate the exact mechanism of bronchogenic nonsquamous carcinoma development.

\section{Acknowledgements}

We thank Brian Eyden $\mathrm{PhD}$ and Ric Swindell (Christie Hospital, Manchester, UK) for help with English language and statistical analysis, respectively. We also thank Jian Chen, $\mathrm{PhD}$, for his help in preparation of the figures.

\section{References}

1 Parkin DM, Bray F, Ferlay J, et al. Global cancer statistics, 2002. CA Cancer J Clin 2005;55:74-108.

$2 \mathrm{Li} \mathrm{LD,} \mathrm{Rao} \mathrm{KQ,} \mathrm{Zhang} \mathrm{SW,} \mathrm{et} \mathrm{al.} \mathrm{Statistical} \mathrm{analysis} \mathrm{of}$ data from 12 cancer registries in China, 1993-1997. ZHONGGUO ZHOULIU 2002;11:497-508.

3 Cazorla M, Hernandez L, Fernandez PL, et al. K-ras gene mutations and absence of p53 gene mutations in spontaneous and urethane-induced early lung lesions in CBA/J mice. Mol Carcinogen 1998;21:251-260. 
4 Kosma VM, Lang PS, Servomaa MK, et al. Association of p53, K-ras and proliferating cell nuclear antigen with rat lung lesions following exposure to simulated nuclear fuel particles. Cancer Detect Prev 1999;23: 194-203.

5 Thiberville L, Payne P, Vielkinds J, et al. Evidence of cumulative gene losses with progression of premalignant epithelial lesions to carcinoma of the bronchus. Cancer Res 1995;55:5133-5139.

6 Fiala ES, Sohn OS, Wang CX, et al. Induction of preneoplastic lung lesions in guinea pigs by cigarette smoke inhalation and their exacerbation by high dietary levels of vitamins $\mathrm{C}$ and E. Carcinogenesis 2005;26:605-612.

7 Bota S, Auliac JB, Paris C, et al. Follow-up of bronchial precancerous lesions and carcinoma in situ using fluorescence endoscopy. Am J Respir Crit Care Med 2001;164:1688-1693.

8 Pasic A, Vonk-Noordegraaf A, Risse EK, et al. Multiple suspicious lesions detected by autofluorescence bronchoscopy predict malignant development in the bronchial mucosa in high risk patients. Lung Cancer 2003;41:295-301.

9 Wistuba II, Behrens C, Virmani AK, et al. High resolution chromosome $3 p$ allelotyping of human lung cancer and preneoplastic/preinvasive bronchial epithelium reveals multiple, discontinuous sites of $3 p$ allele loss and three regions of frequent breakpoints. Cancer Res 2000;60:1949-1960.

10 Martin B, Verdebout JM, Mascaux C, et al. Expression of p53 in preneoplastic and early neoplastic bronchial lesions. Oncol Rep 2002;9:223-229.

11 Hirano $\mathrm{T}$, Franzen B, Kato $\mathrm{H}$, et al. Genesis of squamous cell lung carcinoma. Sequential changes of proliferation, DNA ploidy, and p53 expression. Am J Pathol 1994;144:296-302.

12 Wistuba II, Behrens C, Milchgrub S, et al. Sequential molecular abnormalities are involved in the multistage development of squamous cell lung carcinoma. Oncogene 1999;18:643-650.

13 Miller RR. Bronchioloalveolar cell adenomas. Am J Surg Pathol 1990;14:904-912.

14 Mori M, Chiba R, Takahashi T. Atypical adenomatous hyperplasia of the lung and its differentiation from adenocarcinoma. Characterization of atypical cells by morphometry and multivariate cluster analysis. Cancer 1993;72:2331-2340.

15 Nakayama H, Noguchi M, Tsuchiya R, et al. Clonal growth of atypical adenomatous hyperplasia of the lung: cytofluorometric analysis of nuclear DNA content. Mod Pathol 1990;3:314-320.

16 Koga T, Hashimoto S, Sugio K, et al. Lung adenocarcinoma with bronchioloalveolar carcinoma component is frequently associated with foci of high-grade atypical adenomatous hyperplasia. Am J Clin Pathol 2002;117:464-470.

17 Chapman AD, Kerr KM. The association between atypical adenomatous hyperplasia and primary lung cancer. Br J Cancer 2000;83:632-636.
18 Travis WD, Brambilla E, Müller-Hermelink HK, et al. World Health Organization Classification of Tumours: Pathology \& genetics. In: Travis WD, Brambilla E, Müller-Hermelink HK et al (eds). Tumours of the Lung, Pleura, Thymus and Heart. Lyon, France, March 12-16, 2003, pp 68-73.

19 Auerbach O, Forman JB, Gere JB, et al. Changes in the bronchial epithelium in relation to smoking and cancer of the lung; a report of progress. N Engl J Med 1957;256:97-104.

20 Auerbach O, Stout AP, Hammond EC, et al. Changes in bronchial epithelium in relation to cigarette smoking and in relation to lung cancer. N Engl J Med 1961; 265:253-267.

21 Nagamoto N, Saito Y, Sato M, et al. Lesions preceding squamous cell carcinoma of the bronchus and multicentricity of canceration-serial slicing of minute lung cancers smaller than $1 \mathrm{~mm}$. Tohoku J Exp Med 1993; 170:11-23.

22 Solomon MD, Greenberg SD, Spjut HJ. Morphology of bronchial epithelium adjacent to adenocarcinoma of the lung. Mod Pathol 1990;3:684-687.

23 Chyczewski L, Chyczewska E, Niklinski J, et al. Morphological and molecular aspects of cancerogenesis in the lung. Folia Histochem Cytobiol 2001; 39:149-152.

24 Ullmann R, Bongiovanni M, Halbwedl I, et al. Bronchiolar columnar cell dysplasia-genetic analysis of a novel preneoplastic lesion of peripheral lung. Virchows Arch 2003;442:429-436.

25 Ol'khovskaia IG. Epithelial dysplasia of the bronchi and lung cancer. Arkh Patol 1985;47:20-25.

26 Kerr KM. Pulmonary preinvasive neoplasia. J Clin Pathol 2001;54:257-271.

27 Chyczewski L, Niklinski J, Chyczewska E, et al. Morphological aspects of carcinogenesis in the lung. Lung Cancer 2001;34:S17-S25.

28 Greenberg AK, Yee H, Rom WN. Preneoplastic lesions of the lung. Respir Res 2002;3:20.

29 McDowell EM, Becci PJ, Schurch W, et al. The respiratory epithelium. VII. Epidermoid metaplasia of hamster tracheal epithelium during regeneration following mechanical injury. J Natl Cancer Inst 1979; 62:995-1008.

30 Ferron PE, Bagni I, Guidoboni M, et al. Combined and sequential expression of p53, Rb, Ras and Bcl-2 in bronchial preneoplastic lesions. Tumori 1997;83: 587-593.

31 Pendleton N, Dixon GR, Green JA, et al. Expression of markers of differentiation in normal bronchial epithelium and bronchial dysplasia. J Pathol 1996;178: 146-150.

32 Fisseler-Eckhoff A, Erfkamp S, Muller KM. Cytokeratin expression in preneoplastic lesions and early squamous cell carcinoma of the bronchi. Pathol Res Pract 1996;192:552-559.

33 Janout V, Siroky P, Novak J, et al. Lung cancer incidence in the Czech Republic: a time-trend study. Onkologie 2004;27:376-379. 